Observations at the Stockholm Observatory were interfered with by heavy skies, but Dr. Bohlin reports that some photographs were obtained on orthochromatic plates used in conjunction with a yellow screen.

Further negative results, accruing from careful observations made on May i8 and the following days, are recorded by Father S. Chevalier in a special circular from the Lô-Sè Observatory. The sun was observed directly and by projection by several observers, but no trace of the comet was seen on the disc about the computed time of transit. Photographs were also obtained, and clearly showed dark

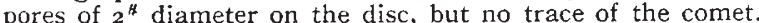
It therefore appears unlikely that any part of the comet having a diameter of $0.5^{\prime \prime}$, or, actually, $60 \mathrm{~km}$., was dense enough to be registered on the plate. The magnetic curves, of which reproductions accompany the circular, obtained at the Lu-Kia-Pang Observatory on May 17,18 , and 19 , show no perturbations which could with certainty be ascribed to cometary influence.

The Comptes rendus for June 13 (No. 24) contains several interesting notes concerning observations of the comet at various observatories.

M. Marchand reports that at the Pic-du-Midi station the solar halo seen from May ig to 25 was still visible on May $3 \mathrm{I}$ and June 2 with the same diameter, $3^{\circ}$ or $4^{\circ}$, but much paler, and a notable sunset effect was seen on May $3 i$. Such an effect has not been recorded for several years, and is ascribed to the presence of very tenuous matter in the atmosphere at great altitudes.

MM. Cirera and Pericas describe the varying forms of the comet as observed at the Observatoire de I'Ébre (Spain) from May $x$ to June 6 . A table of the apparent and real lengths-the latter given in astronomical units-shows that up till May 12 the increase in the length of the tail was continuous, but a decrease was noted on May 26 , followed by further progressive increase until June 2 ; observations on some of the intermediate dates were interfered with by clouds. It is suggested that the fluctuation was possibly produced by the earth capturing several million kilometres of the tail during the predicted passage on May 19. Photosraphs were secured on a number of dates during May and the first week in June, but bad weather prevented a continuous series from being obtained. The series shows however, some striking changes in the form, extent, and brightness of the nucleus and head, especially about May 27 ; on May 30 the coma was much less bright and extensive.

M. Eginitis reports on the observations of the tail, made at the Athens Observatory on May 18, 19, and 20. On the Thursday morning, about an hour before the computed time of passage, the tail was seen to be nearly straight, but having a slight curvature, which may have been due to the proximity of the earth to the comet's orbit plane. At 3 o'clock on the Friday morning the tail was nearly $130^{\circ}$ long, but no trace of it could be found on the Saturday morning. On the Friday evening, however, it was seen, like a crescent moon, and on Saturday evening was some $30^{\circ}$ long. Observations of the sun's disc during the time of transit failed to reveal any sign of the comet.

MM. J. Baillaud and Boinot discuss, in detail, the transformations of the nucleus depicted on the photographs taken at the Paris Observatory on May 30 and $3 \mathrm{I}$ and June 2. A sudden transformation took place in the nucleus on May 3I, the previously extensive elliptical form giving way to a circular condensation with bright extensions. Secondary condensations appeared, some of which were only temporary; but one of them persisted undiminished until June 2, and the authors liken the phenomenon to the doubling which occurred in the case of Bicla's comet.

In No. 6, vol. lxx., of the Monthly Notices (R.A.S.) Dr. Rambaut publishes positions of the comet determined from photographs secured at the Radcliffe Observatory, with the 24 -inch telescope, between November $\%$, I909, and February II. Such places depending upon stars generally taken from the Astrographic Catalogue will be invaluable in the subsequent discussions of the orbit; the comet was first picked up at the Radcliffe Observatory on November 5 , igog.

Mr. H. H. Gruning, of Ealing, sends us an interesting account of his observations of the comet. Between April is and June 18 , using five-times field glasses (2-inch aperture), he saw the comet fourteen times, and on ten of these occasions it was visible to the naked eye. No tail was seen except on May $3 \mathrm{I}$ and June I, when, with the glasses, ha was able to follow it to a distance of $\mathrm{I}^{\circ}$. These carefully made observations well illustrate, when compared with the glowing reports from lower latitudes, the disadvantages under which we, in this country, have laboured during the present return of the famous comet.

Another correspondent sends us a cutting from the Lancashire Daily Post for June I, in which Mr. L. Whitaker reports a remarkable phenomenon observed at Salterforth at about $3.30 \mathrm{a} . \mathrm{m}$. on May 26. According to this report, a tail about $40^{\circ}$ in length was seen rising from the eastern horizon. It would be of interest to hav further records of this curious phenomenon.

\section{THE ROYAL SOCIETY OF NEW SOUTH WALES.}

THE Royal Society of New South Wales is the oldest scientific society in Australasia and in the southern hemisphere, unless there are older ones in South America or South Africa, and it will be able to celebrate its centenary in another eleven years.

It was started in $182 \mathrm{I}$ in a similar way to the Royal Society of London, under the name of the Philosophical Society of Australasia, by a small band of friends, ten in number, under the presidency of the Governor, Sir Thomas Brisbane, K.C.B., F.R.S., who met at each other's houses, where papers were read and discussed; there was a penalty of rol. for any member failing to present a paper in his turn. They also lent each other books, as there was no public library in those days and hardly a bookseller in the whole of Australia.

The first members were Mr. Alexander Berry, whose brother, Mr. David Berry, died in 1889 at the age of ninetyseven, and left roo,oool. to his Alma Mater, St. Andrews University, N.B., and the same amount to found a hospital in New South Wales-the writer of this, a member of the society, knew Mr. A. Berry, and thus the chain of membership has been kept up since 1821; Dr. Henry Grattan Douglas, who in after years was one of the prime movers in founding the first university of Australia, viz. the University of Sydney; Judge Barron Field, of the Supreme Court of Australia, author of a work upon Australia, published by John Murray in London in 1825; Major Goulburn, Colonial Secretary; Mr. Patrick Hill, Colonial Surgeon; Captain Philip Parker King, R.N., afterwards F.R.S. and Rear-Admiral, a son of Philip Gidley King, third Governor of New South Wales, who surveyed the north coast of Australia, and later on was engaged in the Adventure and Beagle surveying expedition along the coast of South America-it is interesting to note that the Hon. Philip Gidley King, M.L.C., a son of Admiral Philip Parker King, born in 1817 , served as an officer on board the Beagle with Charles Darwin, and was a member of the society until four or five years ago; Lieut. John Oxley, R.N., Surveyor-General, who was one of the distinguished early explorers in Australia; Dr. Charles Staggard Rumker, astronomer, who started the first observatory in Australia; and Mr. Edward Wolstonecraft. As previously stated, the Governor, Sir Thomas Brisbane, F.R.S., was the president. For many years the Governor of Australia, and later of New South Wales up to 1874 , was always the president, and some of the earlier ones, like Sir T. Brisbane and Sir W. Denison, F.R.S. (afterwards, for a short time, Governor-General of India), were men of scientific attainments who not only took a special interest in the society, but attended its meetings regularly and contributed several papers.

Some of the first papers read before the society were collected by His Honour Judge Barron Field, and published by John Murray in a book entitled "Geographical Memoirs of New South Wales," and it is interesting to note that the subjects which engaged the attention of the members in those early days are typical of the majority of the papers presented to the society ninety years later e.g. the following were amongst those read in 1822 :(I) on the aborigines of New Holland and Van Diemen's Land, by Barron Field; (2) on the geology of part of the coast of New South Wales, by Alexander Berry; (3) on the astronomy of the southern hemisphere, by $\mathrm{Dr}$. 
Rumker; (4) on the maritime geography of Australia, by Captain Philip Parker King, R.N.

After a period of inactivity the society was resuscitated in $185^{\circ}$ under the title of the "Australian Philosophical Society," instead of Australasian, because, as the colony of Tasmania had been taken out of New South Wales in 1825, the term Australasian was no longer applicable. In 1856 the name was again altered, this time to that of Philosophical Society of New South Wales, a further slice of New South Wales having been cut off to form the colony of Victoria. In 1866, by permission of H.M. Queen Victoria, it assumed its present title of "Royal Society of New South Wales," and in I88I it was incorporated by an Act of the New South Wales Parliament.

The principal reason for discarding the term "Philosophical" was because the object and work of the society could not be considered as coming under the head of philosophy, and as the ground covered by the Royal Society of London was so well known, the then members decided to apply to the Crown for permission to use the more comprehensive title of "Royal"; this title had already been granted to the corresponding society in Tasmania. In later years the Philosophical Societies of Victoria, South Australia, and Queensland also changed their names in the same way.

The society was not in a position to publish until 1862 prior to that date some of its papers were printed in the daily newspapers, and others, up to 1859 , appeared in the Sydney Magazine of Science and Art; several of these early papers are still of value, apart from the interest attached to the efforts of the authors to do what they could for the progress of science in a new country; and all honour is due to the early pioneers, for they worked under great difficulties, without the aid of libraries, collections, and modern instruments and appliances, and at a time when it took from six to nine months to get a reply from home, and their work should not be forgotten.

So early as 185 i the society endeavoured to encourage the development of the natural resources of the coknny by offering gold medals for the growth and production of madder, cotton, and sugar, and for the extraction of metals from colonial ores.

Later on, to stimulate and encourage scientific research, the society for some years, viz. from 1882 to 1896 , offered a medal (and a grant of $25 \mathrm{l}$. to help defray the expenses of the investigations) for original researches and observations upon certain specified subjects, of which notice was given three years in advance, but after fourteen years' experience it was decided to discontinue these competitions. The following list gives an idea of the range of the subjects:- the chemistry of the Australian gums and resins; the tin deposits of New South Wales; the iron ore deposits of New South Wales; the marine fauna of Port Jackson; the silver ore deposits of New South Wales; on the origin and mode of occursence of gold-bearing veins and of the associated minerals; influence of the Australian climate in producing modifications of diseases; on the Infusoria peculiar to Australia; anatomy and life-history of the Platypus and Echidna; anatomy and life-history of Mollusca peculiar to Australia; the chemical composition of the products from the so-called kerosene shale of New South Wales.

The society now awards one medal only, viz. the medal which was established, together with a lectureship, in memory of the late Rev. W. B. Clarke, F.R.S.; amongst the non-resident recipients of this medal have been :- Sir Richard Owen, F.R.S., 1878; Prof. George Bentham, F.R.S., 1879 ; Prof. Huxley, F.R.S., 1880; Prof. James Dwight Dana, 1882; Baron von Mueller, 1883; Alfred R. Selwyn, F.R.S., 1884; Sir Joseph Dalton Hooker, 1885.

From 1866 to 1875 the papers read before it were published under the title of "Transactions," but this was considered rather pretentious, and in 1876 they were brought out as the "Journal and Proceedings" as an annual volume; later they were issued for a few years in parts, and this method has been revived.

The volumes, of which forty-three have been issued, vary in size, but those for the last thirty years run from 300 to more than 600 pages. They are well printed in good type on good paper, and well illustrated.

The papers naturally are, for the most part, devoted to
Australasian subjects; those upon astronomy, meteorology, geology, mineralogy, botany, ethnology, water supply and irrigation, and similar matters bulk most largely; some of the papers are, and will remain, of permanent interest. The first eleven volumes are out of print and are difficult to obtain, but, fortunately, the volumes have been widely distributed to public institutions and societies in all parts of the world, so that anyone really interested can generally manage to refer to them.

It is not proposed to give any specific account or review of the recently published volumes, inasmuch as abstracts of all the principal papers read have appeared in the columns of NATURE month by month during recent years under the head of "Societies and Academies." The volume for 1909 has been issued in four parts instead of the single annual volume, in the hope that its usefulness may be increased, and the society is to be congratulated upon having done so.

In I 875 a series of sections was inaugurated in order that the members might be able to meet together for the discussion of matters of scientific interest with less formality than at the ordinary meetings of the society some of these were very successful, and they helped to make the society more popular, and the number of members rapidly increased to 494 , the largest during its history but of late years interest in the sections has decreased. The medical section was a very active one for several years, and did useful work until it was superseded by the formation of an outside independent professional society.

The engineering section is at the present the only active one, and it is doing extremely good work, as shown by the papers and proceedings appearing in the society's volumes; it practically supplies all the advantages afforded by an independent society, and, further, has the use of the Royal Society's library, meeting rooms, printer, office staff, \&c., without any extra subscription.

Most of the other sections will probably re-awaken to their former activity in due course. The sections are:A, mathematics, physics, astronomy, meteorology, \&c. $B$, chemistry and mineralogy, and their application to the arts and agriculture; $C$, geology and palæontology; D, botany and zoology; E, microscopical science; F, geography and ethnology; $G$, literature and the fine arts, including architecture; $\mathrm{H}$, medical science; $\mathrm{I}$, sanitary and social science and statistics; $J$, engineering science; $\mathrm{K}$, economical science.

The society distributes its publications to about 400 similar societies, institutions, and public libraries, not only to all parts of the British Empire, Europe, and America, but to China, Japan, Mexico, the Philippines, Straits Settlements, Chili, Peru, Mauritius, Brazil, \&c., and in almost all cases receives publications from these places in exchange. At one time the society undertook the collection and delivery of scientific publications for other institutions in New South Wales, but this is now done by the Government Bureau for Scientific Exchanges. In addition to the exchange of publications, the society endeavours to maintain touch with scientific workers in other parts of the world by appointins a limited number of non-resident men of science as honorary members; the society has had special pleasure in the acceptance of its honorary membership by such men as Darwin, Hooker, Wallace and others, who have done scientific work in Australasia and Oceana.

In addition to its ordinary meetings, the society arranges for series of popular lectures, to which friends of the members are freely invited, and short courses of lectures are also given upon the geology of Australasia, known as the Clarke lectures, founded in memory of the Rev. W. B. Clarke, F.R.S., a former president of the society, who gave a large part of a long life to geological research in Australia.

It also gives an annual conversazione, which is held at the University, on account of the extensive and suitabie accommodation afforded by it, as the conversazione is very popular and largely attended; all the scientific departments. laboratories, the libraries, and lecture rooms are thrown open for the occasion, and suitable exhibits of new apparatus and specimens are shown in them, as well as experiments and practical illustrations where possible. Lecturettes are given upon recent discoveries or matters of interest.

NO. 2 I 2 I, VOL. 83] 
Usually some of the visitors attending the lectures and conversazione become sufficiently interested to join the society and become useful members; the University also profits in turn, as the conversazione enables many persons to see it and learn what it is doing who otherwise would not have an opportunity.

The society does not restrict itself to work which is done by its own members, but, where possible, it is always willing to assist others; e.g. it greatly assisted in the formation of the Australasian Association for the Advancement of Science; it also took an active part in the foundation of a marine biological laboratory near the entrance to Sydney Harbour, which, unfortunately, was required a few years afterwards by the Government for defence purposes, and it is to be hoped that the trustees, who received compensation from the Government, will see their way before long to start a new marine station and laboratory; it has on several occasions brought matters of importance under the notice of the Government where legislation has been necessary for the good of the public health, the preservation of the native fiora and fauna, also for the assistance of scientific exploring expeditions in the Antarctic and elsewhere and in other similar matters, and it has helped in the extension of the British Science Guild in Australia.

For many years it has been one of the main objects of the society to get together a good library of the principal British, American, French, German, and other scientific journals, and it now has complete series of many of these, some by purchase, others by gift and in exchange for its own publications, so that, taking the limited resources of the society into account, quite a creditable and useful library has been gradually built up. Without such books of reference the research student is at a great disadvantage, and the society regards the formation of such a reference library as of equal importance to the publication of papers read before it.

In 1878 the society obtained possession of its present freehold premises in Elizabeth Street, Sydney. Since then it has twice added to them, in 1896 and again in 1905 ; the last time it was to increase the accommodation required for the growing library, and also to provide accommodation for kindred societies by sub-letting some of the rooms, not immediately required, to them at low rentals; in this way it affords (as was stated in an article on the Australasian Association for the Advancement of Science, NATURE, December 30, 1909) some of the advantages enjoyed by the English societies in Burlington House.

The Parliament of New South Wales has generously helped the society for some years; for several years the Government printed the society's annual volume of papers and proceedings; of late years, in place of printing the volume, it has contributed ros. per annum for each 20 s. of the members' subscriptions; but, in spite of this, the society's income is insufficient to enable it to undertake many things it would like to do for the advancement of science, and it finds difficulty in carrying on its present efforts.

A. Liversidgr.

\section{THE AMERICAN PHILOSOPHICAL SOCIETY.}

THE general meeting of the American Philosophical Society was held at Philadelphia on April 21-23, and we have been favoured by the secretaries with a report of the proceedings. The afternoon of April 23 was devoted to a symposium on experimental evolution, the principal papers being given by Prof. H. S. Jennings, on inheritance in non-sexual and self-fertilised organisms; Mr. G. H. Shull, on germinal analysis through hybridisation; and Dr. C. B. Davenport, on new views about reversion.

At the session on April 22 the following were elected to membership:-Residents of the United States: Dr. S. E. Baldwin, Dr. F. G. Benedict, Dr. C. F. Brush; Dr. D. H. Campbell, Dr. W. E. Castle, Dr. G. B. Gordon, Dr. D. J. Hill, Dr. H. C. Jones, Dr. L. Loeb, Mr. J. McCrea, Dr. R. C. Maclaurin, F.R.S., Dr. B. O. Pierce, Dr. H. F. Reid, Dr. J. F. Rhodes, and Dr. O. W. Richardson. Foreign residents: Dr. A. von Baeyer, Madame S. Curie, Sir David Gill, K.C.B., F.R.S., Dr. E. if $x_{y}$ y, and M. C. E. Picard. O. 2 I 2 I, VOL. ?? ?
In addition to the symposium on evolution, fifty-one papers were presented. Brief summaries of the contents of a few of these papers are subjoined.

Physical notes on Meteor Crater, Arizona, Prof. IV. F. Magie. Meteor Crater is a vast crater situated in Coconino County, Arizona, formed by the impact of an iron meteorite or group of meteorites. Scattered specimens of these meteorites (the Canyon Diablo siderites and the "shale ball" siderites) are found around the crater, but the main mass has not yet been found. It probably is buried 1000 feet below the surface. (I) The Canyon Diablo iron shows a magnetic permeability not very different from that of cast iron. The shale ball iron seems to be generally similar to it in its magnetic properties. Several observations indicate an intrinsic magnetisation, peculiarly arranged, in the shale ball iron. The magnetic field of the crater shows no local peculiarities such as would be expected from the presence of a large continuous mass of iron. The inference is that the mass is fragmentary, perhaps intrinsically magnetised, and also, perhaps, largely oxydised. (2) The distribution of the ejected material and the inclinations of the exposed strata around the crater wall show a remarkable symmetry with respect to a nearly north and south axis. This symmetry, even in details, appears in holes made by bullets in a suitable mass of compacted powder. The inference is that the crater was formed by a projectile. (3) The mass ejected is estimated at 330 million tons. The energy used to lift it out of the hole is a negligible fraction of the energy expended. Most of the energy expended was used in crushing the rock. An estimate based on the assumption that the powdered sandstone was heated to $2500^{\circ} \mathrm{C}$. would indicate an expenditure of $92.5 \times 10^{12} \mathrm{ft}$. tons of energy. Talsing everything into account, it seems reasonable to estimate in all an expenditure of $60 \times 10^{12} \mathrm{ft}$. tons of energy. Taking this for the energy expended, and estimating the prabable velocity of the meteor as lying between three and forty-eight miles a second, the mass of the meteoric group would lie between fifteen million and sixty thousand tons. The size and shape of the crater lead one to estimate a mass larger than this lowest limit, and the final estimate is that the mass is 400 thousand tons, and that its velocity was from eighteen to twenty miles a second.

The conversion of the energy of carbon into electrical energy by solution in iron, Prof. Paul R. Heyl. It is found that carbon dissolves in molten iron with a liberation of energy, which, by providing a suitable negative element, may be obtained as an electric current. The electromotive force thus developed has not yet been definitely determined, but is probably not more than oneor two-hundredths of a volt. There is no possibility of compounding this electromotive force with the accompanying thermal effect, as the two are opposite in direction.

The one-fluid theory of electricity, Prof. F. E. Nipher. The author has shown in a former paper that what have been taken for discharges from the positive terminal of an electrical machine are really optical illusions. The positive discharge is really an inflow of the electrical discharge which flows outward from the negative terminal. This is in harmony with the one-fluid theory of Franklin. With this paper he presents photographic plates showing the discharge from its first stages until the disruptive spark appears. These plates fully confirm the former conclusion that there is no positive electrical discharge. The discharge comes from the negative terminal and goes to the positive. The illusion which has led to the idea of a positive discharge is compared to one which might prevail if Niagara Falls should suddenly recede from Lake Ontario to Lake Erie. It might deceive us into the idea that there had been a positive discharge into Lake Erie.

The past and present status of the rther, Prof. A. G. Webster. The history of the conception of the luminiferous æther was covered from the time of Newton and Huygens to the present. For the last hundred years the belief in the æether as necessary to transmit light has been universal. Lord Kelvin devoted most of his life to establishing its properties. The various mechanical theories were succeeded by Maxwell's successful electromagnetic theory, confirmed twenty years later by the electric wave experiinents of Hertz. "To explain astronomical aberration and the phenomena due to the earth's motion, Maxivell's theory $\because a j$ je:srely strained, and was perfected by Lorentz. The 